\author{
S. Samaropoulou, P. Bareka \& G. Kamari
}

\title{
Biodiversity of the genus Fritillaria (Liliaceae) in Greece
}

\author{
Samaropoulou, S., Bareka, P. \& Kamari, G.: Biodiversity of the genus Fritillaria (Liliaceae) in \\ Greece. — Bocc. 28: 221-222. 2019. — ISSN: 1120-4060 printed, 2280-3882 online. \\ Key words: karyology, hybrodization, taxonomy.
}

Fritillaria L. is a genus of perennial bulbous plants, very important from a taxonomic, pharmaceutical, horticultural and karyological point of view. Greece has been characterized as an evolutionary centre of the subgenus Fritillaria L. since there are at least 31 taxa, most of them endemic to the country. Following both morphological and biogeographical data, Greek Fritillaria taxa can be classified into smaller groups.

The chromosome number $2 n=2 \mathrm{x}=24$ is common among Greek representatives of the genus, except from $F$. montana $(2 n=2 \mathrm{x}=18)$. The karyotypes are asymmetrical, consisting of one metacentric and one submetacentric chromosome pair, while the rest are acrocentrics and subtelocentrics. In order to define the differences among the generally similar karyotypes, differentiations such as the presence and morphology of satellited chromosomes, secondary constrictions and B-chromosomes are always emphasized and chromosomes characterized as meta- and submetacentric, satellited or bearing secondary constrictions, are studied as markers. Moreover triploidy $(2 n=3 \mathrm{x}$ $=36$ and $2 n=3 \mathrm{x}=27$ ) has been referred for a few Greek Fritillaria taxa.

Hybridization in the genus is reported as rare, however in Greece hybrids have been found at areas where two or more taxa co-exist. These hybrids are characterized by morphologically intermediate forms and karyologically different karyotype morphology, ploidy levels and number of B-chromosomes.

The morphological and karyological variety prove the genus is evolving. Hybridization is a very important key to evolution as it can lead to gene flow and consequently to many possible genotypes, sometimes more adaptable to the environment than their parents. In addition, B-chromosomes and polyploidy lead to important genome size variation and consequently to speciation. But what remains as a 
222 Samaropoulou \& al.: Biodiversity of the genus Fritillaria (Liliaceae) in Greece.

question is whether these procedures are responsible for the great number of Fritillaria taxa in Greece.

Addresses of the authors:

Sofia Samaropoulou ${ }^{1}$, Pepy Bareka ${ }^{1}$ \& Georgia Kamari ${ }^{2}$,

${ }^{1}$ Laboratory of Systematic Botany, Faculty of Crop Science, Agricultural

University of Athens, Iera Odos 75, GR-11855, Athens, Greece. E-mail: s.samarop@aua.gr, bareka@aua.gr

${ }^{2}$ Botanical Institute, Section of Plant Biology, Department of Biology, University of Patras, GR-26500, Patras, Greece. E-mail: kamari@upatras.gr 